\title{
Identification, characterization and mapping of EST-derived SSRs from cacao-Ceratocystis cacaofunesta interaction
}

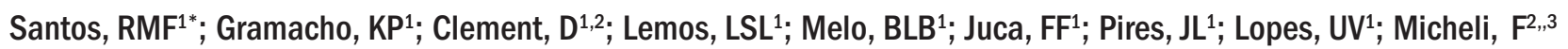 \\ ${ }^{1}$ Cocoa Research Center, CEPLAC/CEPEC, 45600-970 Itabuna-BA, Brasil \\ ${ }^{2}$ CIRAD, UMR DAP, Avenue Agropolis TA96/03, 34398 Montpellier cedex 5, France \\ ${ }^{3}$ UESC, DCB, Centro de Biotecnologia e Genética, Rodovia Ilhéus-Itabuna Km 16, 45662-900 Ilhéus-BA, Brasil.
}

*E-mail: rogeriomerces@ceplac.gov.br

Keywords: Ceratocystis wilt; microsatellites; molecular breeding; resistance; mapping

Ceratocystis cacaofunesta is an ascomycete responsible for the lethal wilt disease of cacao (Theobroma cacao L.). Marker-assisted selection combined with conventional breeding is one way in which the cacao resistance to Ceratocystis wilt can be improved. In this study, we screened a set of ESTs obtained from cacao elicited with $C$. cacaofunesta to identify ESTSSRs and test their efficacy for mapping. Among the 3,432 ESTs analyzed, 384 contained SSRs and 428 EST-SSRs were identified, mainly dinucleotides (78.5\%), com 4 numbers of repeats (75.23\%), and preferentially AG/CT motif (25.47\%). GO function was assigned to the ESTs containing SSRs: 4.04\% belonged to "defense response" category, with $20.69 \%$ of them to the sub-category "defense response to fungus". In relation to the ORF, the same amount of EST-SSRs was observed in 5'UTR as well as in the 3'UTR (about 30\%). From the 428 EST-SSRs identified, 12 were polymorphic, revealing a total of 41 alleles. The number of alleles per locus ranged from 2 to 6 , with an average of 3.41. Four EST-SSRs were mapped on the $\mathrm{F}_{2}$ Sca 6 x ICS 1 population segregating for Ceratocystis wilt, which were distributed on the linkage groups 2, 3, 4 and 8 . These markers contributed to saturate the genetic map of the cacao mapping population from CEPEC/ CEPLAC and will be valuable for the research community to improve the cacao breeding program.

Orgão financiador: Fapesb, CEPLAC, CIRAD 